\title{
Effect of High-Intensity whole body vibration on blood lactate removal and heart rate after an all- out test in active young men \\ Efecto de las vibraciones de alta intensidad de cuerpo completo sobre la remoción del lactato sanguíneo y la frecuencia cardiaca luego de una prueba máxima en hombres activos jóvenes \\ *Daniel Galaz-Campos, $* *$ Jorge Olivares-Arancibia, $* * *$ Patricio Solis-Urra, $* * * *$ Ernesto Suarez-Cadenas, *****Alejandro Santos-Lozano, *Fernando Rodríguez-Rodríguez, ${ }^{*}$ Carlos Cristi-Montero \\ *Pontificia Universidad Católica de Valparaíso (Chile), ** Universidad de las Américas (Chile), ***Universidad Andrés Bello (Chile), ****Universidad Pablo de Olavide (España), *****Universidad Europea Miguel de Cervantes (España)
}

\begin{abstract}
Speed up recovery is fundamental in sport disciplines in which competitors must perform repeated trials within the same competition. The main objective of this study was to determine the effect of high-frequency whole body vibration (WBV) on blood [Lac] removal and heart rate (HR) after an all-out test. The participants performed a $4 \times 100 \mathrm{~m}$ all-out test every $48 \mathrm{~h}$ in a random cross-over fashion, and a blood [Lac] removal protocol was applied after each test: a) 20 min seated (REST); b) squatting on a vibrating platform $(\mathrm{S}+\mathrm{V})$; and c) squatting on a non-vibrating platform (S-V). Blood [Lac] and HR were measured at rest, immediately after the 4 x $100 \mathrm{~m}$ all-out test (min 0), and at 10 and 20 min during the removal protocols. The results showed that the 3 protocols displayed significantly decreased blood [Lac] after $20 \mathrm{~min}$ (REST, S+V, and S-V removed $\Delta 6.6 ; \Delta 10.5$; and $\Delta 11.1 \mathrm{mmol}_{\bullet} \mathrm{L}^{-1}$, respectively). However, there were no significant differences in the blood [Lac] removal level between the $\mathrm{S}+\mathrm{V}$ and $\mathrm{S}-\mathrm{V}$ conditions. Interestingly, the $\mathrm{S}-\mathrm{V}$ participants showed increased HR levels during the active recovery compared with the REST and S+V conditions. The effect of high-frequency WBV is not an additional stimulus to increase the blood [Lac] removal capacity in active young men, although WBV appeared to elicit less cardiovascular stress during recovery.
\end{abstract}

Key words: high-frequency vibration; recovery; lactate clearance; heart rate.

Resumen. Acelerar la recuperación es fundamental en las disciplinas deportivas en las que los competidores deben realizar pruebas repetidas dentro de la misma competencia. El objetivo principal de este estudio fue determinar el efecto de la vibración de alta frecuencia de cuerpo completo (WBV) en la extracción de sangre [Lac] y la frecuencia cardíaca (FC) después de una prueba completa. Los participantes realizaron una prueba total de 4 x $100 \mathrm{~m}$ cada $48 \mathrm{~h}$ de forma aleatoria cruzada, y se aplicó un protocolo de extracción de sangre [Lac] después de cada prueba: a) 20 minutos sentado (REST); b) ponerse en cuclillas sobre una plataforma vibratoria (S+V); y c) ponerse en cuclillas en una plataforma no vibratoria (S-V). La sangre [Lac] y la FC se midieron en reposo, inmediatamente después de la prueba total de 4 x $100 \mathrm{~m}$ ( $\min 0$ ), y a los 10 y 20 min durante los protocolos de extracción. Los resultados mostraron que los 3 protocolos mostraron una disminución significativa de la sangre [Lac] después de 20 minutos (REST, S+V y S-V eliminaron $\Delta 6.6 ; \Delta 10.5 ;$ y $\Delta 11.1$ mmol•L-1, respectivamente). Sin embargo, no hubo diferencias significativas en el nivel de eliminación de sangre [Lac] entre las condiciones $\mathrm{S}+\mathrm{V}$ y S-V . Curiosamente, los participantes $\mathrm{S}-\mathrm{V}$ mostraron mayores niveles de FC durante la recuperación activa en comparación con las condiciones REST y S+V. El efecto del WBV de alta frecuencia no es un estímulo adicional para aumentar la capacidad de eliminación de sangre [Lac] en hombres jóvenes activos, aunque el WBV parece provocar menos estrés cardiovascular durante la recuperación.

Palabras claves: vibración de alta frecuencia; recuperación; aclaramiento de lactato; frecuencia cardiaca.

\section{Introduction}

Accelerating physical recovery plays a fundamental role after high intensity training or competitive events in different sport modalities. In this regard, disciplines in which athletes must perform repeated trials within one day, such as athletics, rowing or skiing, are a great challenge to bioenergetic recovery (Messonnier et al., 2013; Mika et al., 2016). The main physiological effect resulting from a short recovery period is the increase in blood [Lac], which has been extensively linked to reductions in physical performance (Messonnier et al., 2013; Mika et al., 2016) and an increase in parasympathetic and sympathetic activation to regulate cardiovascular homeostasis (Imai et al., 1994; Savin, Davidson, \& Haskell, 1982). Therefore, it seems clear that the blood removal [Lac] and recovery of heart rate (HR) are determinants part of the sports performance (Barnett, 2006; Kellmann et al., 2018; Mika et al., 2016).

On one side, during exercise, there is an increase in

Fecha recepción: 17-03-20. Fecha de aceptación: 28-07-20 Carlos Cristi-Montero

carlos.cristi.montero@gmail.com sympathetic activity and a decrease in vagal discharge, which leads to an increase in heart rate, stroke volume, and myocardial contractility to cover the energy demands in the muscles involved (Javorka, Zila, Balhárek, \& Javorka, 2002). The autonomic nervous system plays a central role in cardiovascular homeostasis both during and after exercise (Aubert, Seps, \& Beckers, 2003), thus various methods (e.g., whole body vibration [WBV], water immersion, etc.) have been used to activate the mechanisms that contribute to increasing parasympathetic activity, which causes a decrease in heart rate and promotes cardiovascular recovery after exercise (O'Leary, 1993).

On the other hand, different blood [Lac] removal methods have been proposed to increase athlete's metabolic efficiency (Carrasco, Sañudo, de Hoyo, Pradas, \& Da Silva, 2011; Mika et al., 2016; Mota et al., 2017). To date, scientific evidence shows that active recovery induces higher blood [Lac] removal compared with passive methods (Mika et al., 2016; Mota et al., 2017), since it seems to increase lactate oxidation and gluconeogenesis (Beneke \& Duvillard, 1996; Menzies et al., 2010; Spencer, Dawson, Goodman, Dascombe, \& Bishop, 2008). This is mainly a result of metabolite recycling across increases in the blood flow rate (Cochrane, 2012). 
Therefore, in recent years, new methods of training and recovering have been proposed, among them, a great focus has been placed on the effect of WBV in sports and clinical (Cochrane, 2012; Marin et al., 2012; Olivares-Arancibia et al., 2018).

About WBV method, the mechanical stimulus applied to muscles and tendons could remove blood [Lac] by, (a) increased blood flow to the muscle (Sañudo et al., 2016) and other peripheral tissues (Lohman, Petrofsky, Maloney-Hinds, Betts-Schwab, \& Thorpe, 2007), (b) increased oxygen recovery rate (Coza, Nigg, \& Dunn, 2011), (c) higher energy expenditure (Cochrane, 2011),(d) higher oxygen consumption $\left(\mathrm{VO}_{2}\right)$, and (e) metabolism of by-products (Jimenez et al., 2007). Thus, several studies investigated the impact of WBV on blood [Lac] removal showing mixed results (Carrasco et al., 2011; Dupont, Moalla, Guinhouya, Ahmaidi, \& Berthoin, 2004; Green \& Stannard, 2010; Kang, Min, Yu, \& Kwon, 2017). Most of these studies have applied low-frequency stimulation in a localised fashion, whereas high-frequency WBV studies remain scarce. Therefore, the aim of this study was to investigate the effect of high-frequency WBV protocol on blood [Lac] removal and heart rate (HR) after a maximal effort.

\section{Methods}

The present study was designed according to CONSORT 2010 guidelines (Consolidated Standards of Reporting Trials) (Schulz, Altman, \& Moher, 2011), a checklist intended to improve the quality of reports of randomized controlled trials, consisting of 25 items - 37 points total. In addition, this study uses recommendations of the International Society of Musculoskeletal and Neuronal Interactions (ISMNI) for reporting WBV intervention; including 13 factors of WBV and vibration parameters that considers intensity, amplitude, acceleration, body position, kind of exercise, etc. (Rauch et al., 2010).

\section{Participants}

Eight male students from the grade of sports sciences (18-23 years-old), participated in this study. All of them had practiced football, basketball, or handball on the university team at least two years. Inclusion criteria were: i) men from aged 18-23 years old; ii) active participant of a university sports team organization; iii) training at least three times per week. Exclusion criteria were: i) history of muscular/joint injury in the past 6 months, ii) present any condition incompatible with the protocol of exercise or WBV (i.e., diabetes mellitus, endoprostheses, retina diseases), and iii) participants who missed any evaluation. The present study was conducted according to the international deontological standard for research involving human subjects outlined in the Declaration ofHelsinki (World Medical Association, 2013).All participants signed informed consent and were made aware of procedures and objectives.

\section{Study design}

This study used a crossover design and consisted of two parts. In the first week, the participants were familiarised with the instruments to be used in the research and were performed the anthropometric measurements. In the second week, the experimental setting was carried out. The test was carried out in 3 days separated by $48 \mathrm{~h}$, where each day consisted of $4 \times 100 \mathrm{~m}$ all-out running with a randomly assigned blood [Lac] removal method applied to the participants (20 min seated (REST); squatting on a vibrating platform $(\mathrm{S}+\mathrm{V})$; or squatting on a non-vibrating platform (SV). Randomization was performed through a platform web (https://www.randomizer.org). The exercise intensity of the active blood [Lac] removal protocols (dynamic squats) was controlled by monitoring HR. All the participants were asked to abstain from consuming coffee to avoid strenuous exercise for the $48 \mathrm{~h}$ and maintain their normal diet prior to each test. The tests were all conducted in the morning (between 9 to 12 a.m.), to avoid possible variations in the participants' circadian rhythms (Forsyth \& Farrally, 2000).

\section{Initial measurements}

Anthropometric measurements were obtained during the familiarisation week and were taken in the first hour of the morning (8:00 to 9:30 a.m). These included body weight and body fat percentage using a digital scale calibrated to a precision of $0.1 \mathrm{~kg}$ (model TBF-300A, TANITA ${ }^{\circledR}$, Japan) and height using a stadiometer (model 216, SECA ${ }^{\circledR}$, Germany).

\section{Measurement of cardiorespiratory fitness ( $\mathrm{VO}_{2} \mathrm{max}$ )}

An incremental test was conducted on a treadmill beginning with a 4 min warm-up at a speed of $8 \mathrm{~km} / \mathrm{h}^{-1}(0$ slope). The speed was then increased by $2 \mathrm{~km} / \mathrm{h}^{-1}$ and $1 \%$ slope every $2 \mathrm{~min}$. $\mathrm{VO}_{2}$ max was determined breath-by-breath with an automated gas analyser (Metalyzer, CORTEX ${ }^{\circledR}$, Germany). The $\mathrm{VO}_{2}$ max achievement was considered when participants matched at least three of the following criteria: (a) a $\mathrm{VO}_{2}$ steady state despite the increasing load (changes in $\mathrm{VO}_{2}$ at $\mathrm{VO}_{2} \mathrm{max} \mathrm{d}$ » $150 \mathrm{ml}$ ); (b) a final respiratory exchange ratio greater than 1.1 ; (c) visible exhaustion; or (d) a HR + 10 beats/min of the maximum predicted (220-age) (Carrasco et al., 2011).

\section{The «all-out» test}

Each participant completed a distance of $400 \mathrm{~m}$ of running ( 4 x $100 \mathrm{~m}$ all-out), 3 times (once every $48 \mathrm{~h}$ ). The participants run $100 \mathrm{~m}$ and then turned around to immediately run the next $100 \mathrm{~m}$ at the highest end of the intensity spectrum «allout.» This distance was chosen because exercise above 60 seconds induces higher intramuscular $\mathrm{pH}$ decreases compared to shorter periods (Ross \& Leveritt, 2001). The test time was measured with an electronic chronometer (Globus Tester contact platform, GLOBUS ${ }^{\circledR}$, Italy). Subsequently, blood sampling for [Lac] was assayed after the test (Figure 2).

\section{Blood [Lac] sample}

The sample for blood [Lac] was extracted from the ring finger of the right hand of the participants at rest, 30 seconds after the 4 x $100 \mathrm{~m}$ all-out test (minute 0), and at 10 and 20 minutes after 4 x 100 m all-out test (Kass \& Carpenter, 2009). The finger area was cleaned with $95 \%$ denaturalised alcohol, and the first blood drop was wiped away with a cotton swab. [Lac] was then measured using the second blood drop (Lactate Pro II, ARKRAY ${ }^{\circledR}$, Japan) as previously described 
(ICC $r=0.99$; mean difference $0.08 \pm 0.3 \mathrm{mM}$; a range of mean difference ( \pm 2 SD) - 0.52 to 0.68 ) (Pyne, Boston, Martin, \& Logan, 2000).

\section{Removal protocols on the Whole Body Vibration platform}

Prior to the test, the blood [Lac] removal protocol was assigned at random: a) 20 min seated, indoor, with controlled temperature and conditions (REST); b) 20 min of dynamic squats on a vibrating platform (S+V); and c) 20 min of dynamic squats on a platform without vibration (S-V). Whole Body Vibration stimulus platform, a Fitvibe Excel (Fitvibe, GYMNAUNIPHY ${ }^{\circledR}$, Belgium), was used, which produces a vertical sinusoidal vibration. The $\mathrm{S}+\mathrm{V}$ and $\mathrm{S}-\mathrm{V}$ conditions performed 10 body weight squats during $1 \mathrm{~min}$ on the platform with a rhythmic 3 seconds up (concentric phase) and 3 seconds down (eccentric phase) controlled by a digital metronome (figure 1). The protocol began from a $170^{\circ}$ extension and did not exceed a knee angle flexion of $90^{\circ}$ (Jimenez et al., 2007). After a 1 min rest was allowed, the protocol lasted $20 \mathrm{~min}$. The $\mathrm{S}+\mathrm{V}$ condition intensity reached $30 \mathrm{~Hz}$ with a $4 \mathrm{~mm}$ amplitude, respectively. The magnitude was estimated using the proposal equation of Hawkey (Hawkey, 2012), equivalent to $14.5 \mathrm{~g}$-forces. The S-V condition performed the same platform protocol without the vibration stimulus, and all the subjects wore no shoes and used similar cotton socks to avoid external between-subject variance in damping.

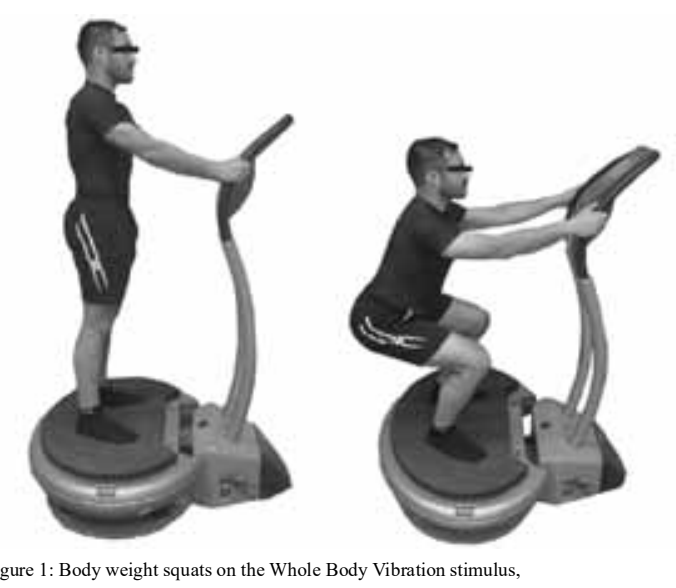

\section{Heart rate measurement}

To compare the cardiovascular load in the 3 removal conditions, exercise, and recovery, the intensity was monitored using a HR telemetric system (Polar Team, Polar Electro ${ }^{\circledR}$, Finland). HR was recorded at REST, after the $4 \mathrm{x}$ $100 \mathrm{~m}$ all-out test and during the $10 \mathrm{~min}$ of active blood [Lac] removal (resting periods were excluded in $\mathrm{S}-\mathrm{V}$ and $\mathrm{S}+\mathrm{V}$ ). The $\mathrm{HR}$ in the $\mathrm{S}+\mathrm{V}$ and $\mathrm{S}-\mathrm{V}$ conditions were monitored to respect the $50-60 \%$ of the reserve HR (Karvonen, Kentala, \& Mustala, 1957; Monedero \& Donne, 2000).

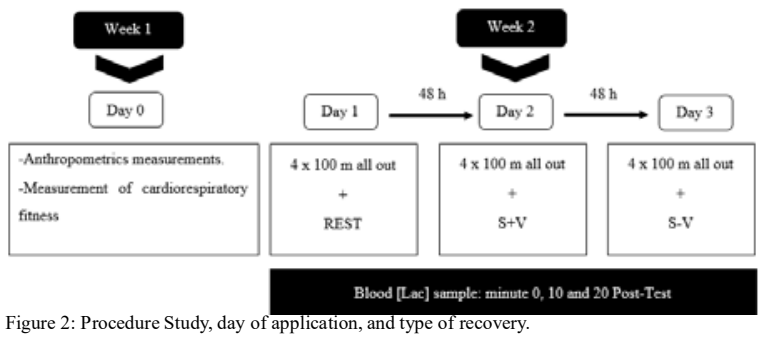

\section{Statistical Analyses}

The values are presented as the means \pm standard deviation (SD). The normality of the data was analysed using the Shapiro-Wilk test because of the small sample size. A two-way ANOVA factor (Time x Condition) was performed to assess the significant main effects of blood [Lac] removal and HR. The Bonferroni post-hoc test was used in all pairwise comparisons when necessary. Cohen's d was calculated to estimate the effect size (Cohen, 1992). The strength of the effect was assessed according to the following interpretation: trivial (0-0.19), small (0.20-0.49), medium (0.50-0.79), and large ( 0.80 and greater) (Cohen, 1992). All statistical analyses were performed using SPSS version 21 (SPSS Inc., Chicago, IL). Significance was set at $p<0.05$.

\section{Results}

\section{Participants}

Participant characteristics are presented in table 1. Overall, all eight male students showed an acceptable percentage of fat and a high level of VO2max $\left(>60 \mathrm{ml} / \mathrm{kg} / \mathrm{min}^{-1}\right)$.

\begin{tabular}{lc} 
Table 1. Characteristics of the participants Mean \pm SD & \\
\hline Age (yrs.) & $21.1 \pm 2.0$ \\
Weight $(\mathrm{kg})$ & $71.0 \pm 7.5$ \\
Height $(\mathrm{cm})$ & $1.77 \pm 0.0$ \\
Fat mass $(\%)$ & $13.8 \pm 2.9$ \\
VO2max $\left(\mathrm{ml} / \mathrm{kg} / \mathrm{min}^{-1}\right)$ & $62.7 \pm 1.9$ \\
Rest Lactate $\left(\mathrm{mmol} \cdot \mathrm{L}^{-1}\right)$ & $1.1 \pm 0.4$ \\
Rest HR (bpm) & $62.5 \pm 3.2$ \\
\hline Note. Data are expressed as mean \pm SD. bpm: beats per minute. $\mathrm{VO}_{2}$ max: maximum rate of \\
\hline
\end{tabular}

\section{Blood lactate results}

The $4 \times 100 \mathrm{~m}$ all-out test was performed in $74.0 \pm 0.04 \mathrm{~s}$, and the rating of perceived exertion was $9.4 \pm 0.7$ points $(0-10$ points) (Borg, 1982). There were no differences on blood [Lac] among the three conditions immediately after the $4 \mathrm{x}$ $100 \mathrm{~m}$ all-out test $\left(p=0.150 ; \mathrm{F}_{(2)}=2.65\right)$.

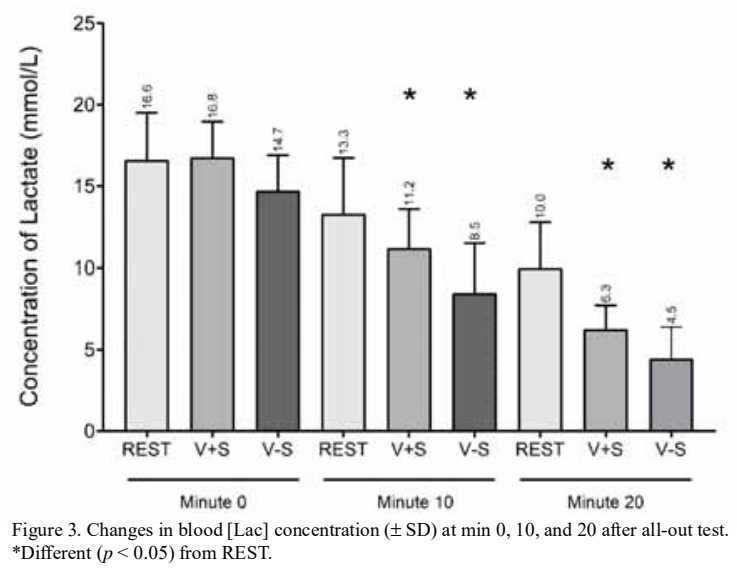

The REST condition presented blood [Lac] of $16.6 \pm 2.9$ mmol $\bullet \mathrm{L}^{-1}$ at the end of the test. At $10 \mathrm{~min}$, blood [Lac] decreased to $13.3 \pm 3.4$ and $10.0 \pm 2.8 \mathrm{mmol} \bullet \mathrm{L}^{-1}$ at $20 \mathrm{~min}$ with a final decrease of $39 \%$. The $\mathrm{S}+\mathrm{V}$ condition presented blood [Lac] of $16.8 \pm 2.2 \mathrm{mmol} \bullet \mathrm{L}^{-1}$ after the $4 \times 100 \mathrm{~m}$ all-out test. At $10 \mathrm{~min}$, [Lac] decreased to $11.2 \pm 2.4 \mathrm{mmol} \bullet \mathrm{L}^{-1}$ and $6,3 \pm 1.5$ $\mathrm{mmol} \bullet \mathrm{L}^{-1}$ at $20 \mathrm{~min}$ with a final decrease greater than $62 \%$. The S-V condition presented blood [Lac] of $15.6 \pm 2.5 \mathrm{mmol} \bullet \mathrm{L}^{-}$ ${ }^{1}$ after the $4 \times 100$ m all-out test. At $10 \mathrm{~min}$, blood [Lac] decreased to $8.5 \pm 3 \mathrm{mmol} \bullet \mathrm{L}^{-1}$ and $4.5 \pm 1.9 \mathrm{mmol} \bullet \mathrm{L}^{-1}$ at $20 \mathrm{~min}$, reaching a total decrease greater than $71 \%$. The results indicate differences among the REST, $\mathrm{S}+\mathrm{V}$, and $\mathrm{S}-\mathrm{V}$ conditions at 
both 10 and $20 \mathrm{~min}$. However, no differences were found between the $\mathrm{S}+\mathrm{V}$ and $\mathrm{S}-\mathrm{V}$ conditions at 10 and $20 \mathrm{~min}$ (Figure $3)$.

To determine the effectiveness of vibration on blood [Lac] removal capacity, the effect size was calculated. The results point to an important effect in the $\mathrm{S}+\mathrm{V}$ and $\mathrm{S}-\mathrm{V}$ conditions compared to the REST condition at 10 and $20 \mathrm{~min}$. However, at 20 min both $\mathrm{S}+\mathrm{V}$ and $\mathrm{S}-\mathrm{V}$ presented a similar and large effect $(d>0.80)$, as shown in Table 2 .

Table 2 .
\begin{tabular}{ccc} 
Effect sizes (Cohen's d) per conditions at 10 in and $20 \mathrm{~min}$. & \\
\hline Time & REST vs. S-V $(95 \% \mathrm{CI})$ & REST vs. S+V $(95 \% \mathrm{CI})$ \\
\hline $10 \mathrm{~min}$ & $1.49(0.21,2.70)$ & $0.71(-0.355,1.737)$ \\
$20 \mathrm{~min}$ & $2.31(0.74,3.82)$ & $1.68(0.348,2.96)$ \\
\hline
\end{tabular}

REST: 20 min seated; S+V: 20 min dynamic squats on a WBV; S-V: 20 min dynamic squats on a platform without vibration.

\section{Removal and heart rate}

Comparing HR, no differences were observed in three of the four points: $\operatorname{REST}\left(p=0.161 ; \mathrm{F}_{(2)}=2.51\right)$, before the allout test $\left(p=0.448 ; \mathrm{F}_{(2)}=0.92\right)$, and at the end of the all-out test $\left(p=0.250 ; \mathrm{F}_{(2)}=1.76\right)$. However, there were significant effect during the active $10 \mathrm{~min}$ (resting period not included) $\left(p=0.050 ; \mathrm{F}_{(2)}=5.14\right)$. Differences were found when comparing the REST condition with the $\mathrm{S}-\mathrm{V}$ condition $(p<$ 0.035). However, no differences were found when comparing the REST vs. $\mathrm{S}+\mathrm{V}$ condition, and $\mathrm{S}+\mathrm{V}$ vs. $\mathrm{S}-\mathrm{V}$ condition, $(p=$ 0.206 and $p=0.306$, respectively) (Figure 4 ).

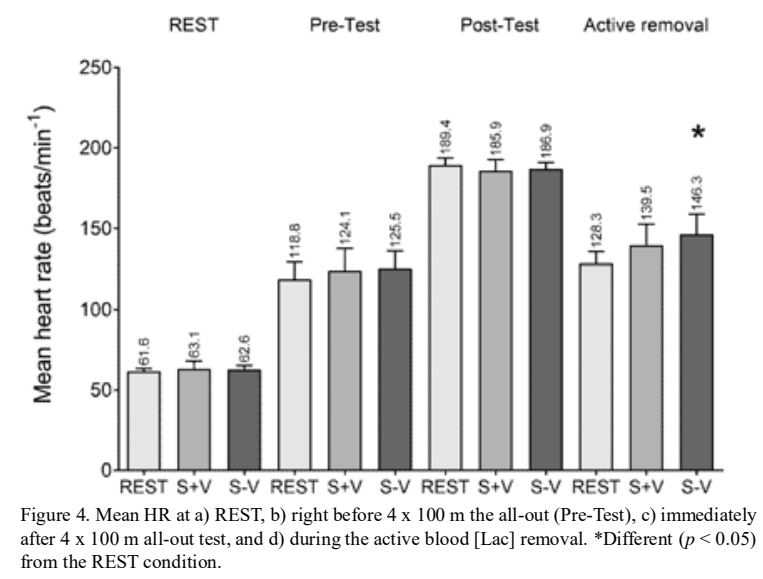

\section{Quality of randomized controlled trial and WBV expe- rimental study}

Regarding the CONSORT guide, this study met the requirements of 27 points, of the total 37 . The following points were not achieved: $3 \mathrm{~b}$ ) Important changes to methods after trial commencement (such as eligibility criteria), 6b) Any changes to trial outcomes after the trial commenced, $7 \mathrm{~b}$ ) When applicable, explanation of any interim analyses and stopping guidelines, 8a) Method used to generate the random allocation sequence, 11a) If done, who was blinded after assignment to interventions (for example, participants, care providers, those assessing outcomes) and how, 11b) If relevant, description of the similarity of interventions, 14a) Dates defining the periods of recruitment and follow-up, 14b) Why the trial ended or was stopped, 23) Registration number and name of a trial registry, and 24) Where the full trial protocol can be accessed, if available.
According to the ISMNI recommendation, this study obtained 11 points of the total 13 . Only two points were not achieved, these are associated with: 7) skidding of feet was evaluated, and 8) changes of vibration settings.

\section{Discussion and conclusions}

This study aimed to investigate the effects of highfrequency WBV on blood [Lac] removal and HR after an allout test. Our findings indicate that active recovery induced large blood [Lac] removal, whereas both active protocols appeared to have a similar effect. However, when accessing HR during active recovery, $\mathrm{S}+\mathrm{V}$ showed reduced cardiovascular demand compared to the $\mathrm{S}-\mathrm{V}$ protocol. Those evidences are complementary to previous research, mostly focused on the application of low-frequency stimulus (Carrasco et al., 2011; Edge, Mündel, Weir, \& Cochrane, 2009; Green \& Stannard, 2010).

This study applied active recovery at $50-60 \%$ of the reserve of HR based on the existing literature, which confirms the effectiveness of active protocols over passive approaches in accelerating blood [Lac] removal (McAinch et al., 2004). Moreover, a WBV stimulus was applied at an intensity that has been shown to increase metabolic rate, temperature, and blood flow (Cochrane, 2012; Figueroa et al., 2012; Jimenez et al., 2007; Borja Sañudo et al., 2016), which may facilitate lactate recycling by different tissues (Hall, Rajasekaran, Thomsen, \& Peterson, 2016).

In this way, our results indicate that active blood [Lac] removal is more efficient compared to passive protocols (Mota et al., 2017). Nevertheless, no significant differences were observed in the blood [Lac] removal rates when comparing the two active protocols. Thus, the WBV did not appear to constitute an additional stimulus to induce blood [Lac] reuse by the organism, similarly to most of the studies on this topic (Carrasco et al., 2011; Dupont et al., 2004; Green \& Stannard, 2010). It is important to note that unlike previous research, the present study included the novelty of using highfrequency vibration. However, it seems not to influence blood [Lac] removal. Despite current results, recent research has been shown a positive impact of low-frequency vibration on blood [Lac] removal after exercise (Kang et al., 2017), so further research is needed to clarify this topic.

Interestingly, $\mathrm{HR}$ values were higher in the $\mathrm{S}-\mathrm{V}$ condition than in the REST condition during 10 min active recovery. This finding suggests that $\mathrm{S}-\mathrm{V}$ participants had an increased cardiovascular load compared with the $\mathrm{S}+\mathrm{V}$ condition, which may indicate that active recovery with high-frequency vibration was slightly more effective. In this regard, the literature has shown that WBV training exerts acute and chronic improvements in vascular function due to the mechanical effect of the vibrations on the muscles, especially improving venous blood return, and increases sympathovagal balance (Figueroa et al., 2012; Sañudo et al., 2016).

In line with the present finding, an interesting study by Sañudo et al. (2013) investigated the effect of vibration as a means of recovery after maximal exercise, showing that the vibration group had a lower HR and increased sympathovagal balance than the group without vibrations. Noteworthy, these 
data differ from the other results (Cheng et al., 2010) that showed that exercise with WBV did not affect $\mathrm{HR}$ recovery at $30 \mathrm{~min}$ post vibration, but is important to note that both protocol and magnitude of the vibrations used in these studies were different (Sañudo et al.: 10.1g vs. Cheng et al.: $2.1 \mathrm{~g})$.

The rationale mentioned above suggests that the HR may decrease with WBV and this fact could be due to two factors: (a) the peripheral vasodilatation generated by highfrequency WBV stimulation, which increases the venous return and raises the stroke volume, thus improving the cardiovascular response without increasing the HR; and (b) a higher heart autonomic modulation. Despite this, both active protocols failed to achieve blood [Lac] lower than 4 $\mathrm{mmol} \bullet \mathrm{L}^{-1}$, which is widely accepted as the anaerobic threshold (Cheng et al., 2010). Therefore, the active protocols herein described are apparently not suitable for quick blood [Lac] removal, considering that [Lac] levels over the anaerobic threshold prior to competition may negatively affect performance (Cristi-Montero et al., 2015; Faude, Kindermann, \& Meyer, 2009). Taken together, these results reinforce previous data regarding the poor effects of WBV on the blood removal of this metabolite (Carrasco et al., 2011; Edge et al., 2009).

However, it is also worth mentioning that three important limitations in this field difficult the interpretation and extrapolation of these results. First, the results obtained should be taken with caution, mainly due to the small sample size. Second, the literature on the use of WBV as a means for exercise recovery is incipient (Marin et al., 2012). Finally, the diverse nature of the available literature considering experimental designs makes comparisons difficult, which may lead to data misinterpretation (Robergs, Ghiasvand, \& Parker, 2004). These involve the participant's position on the platform and the movement (Jimenez et al., 2007; Mester, Kleinöder, \& Yue, 2006), exercise type (Cochrane, 2012; Edge et al., 2009), vibrating devices (Bakhtiary, Safavi-Farokhi, \& Aminian-Far, 2007; Cochrane, Darryl \& Hawke, 2007; Green \& Stannard, 2010), and the intensity applied (Carrasco et al., 2011; Edge et al., 2009; Milanese et al., 2018; Borja Sañudo et al., 2016).

Regarding the latter point, using the formula proposed by Hawkey (2012) for the calculation of the gravitational unit with the use of vibration (frequency, Hz; amplitude, mm), practically all the studies referenced in the present research applied a different intensity (Edge et al. (2009) : 3.5g, Carrasco et al. (2011) : 6.4g, Cochrane \& Hawke (2007): 8.2g, Lohman et al. (2007): 18.1 to $21.7 \mathrm{~g}$ and Jimenez et al. (2007): $14.5 \mathrm{~g}$, among others). In the present study, the intensity was the same as Jimenez et al. (2007), considering a similar scientific approach. Additionally, it is important to note that the $4 \mathrm{x} 100$ $\mathrm{m}$ all-out test in the present study was not performed on a treadmill at a specific percentage of each participant's $\mathrm{VO}_{2} \max$, which decreases the internal reliability of the study. This should be considered in future studies.

In conclusion, active recovery through WBV appears to have no additional effects on blood [Lac] removal rates compared with a no-vibration protocol. However, it does seem to lead to a lower cardiovascular load to reach the same results. Studies with a bigger sample size are needed to confirm our findings.

\section{References}

Aubert, A. E., Seps, B., \& Beckers, F. (2003). Heart rate variability in athletes. Sports Medicine, 889-919

Bakhtiary, A. H., Safavi-Farokhi, Z., \& Aminian-Far, A. (2007). Influence of vibration on delayed onset of muscle soreness following eccentric exercise. British Journal of Sports Medicine, 41(3), 145-148. https:/ /doi.org/10.1136/bjsm.2006.031278

Barnett, A. (2006). Using Recovery Modalities between Training Sessions in Elite Athletes. Sports Medicine, 36(9), 781-796. https://doi.org/ 10.2165/00007256-200636090-00005

Beneke, R., \& Duvillard, S. P. von. (1996). Determination of maximal lactate steady state response in selected sports events. Medicine \& Science in Sports \& Exercise, 28(2), 241-246

Borg, G. A. (1982). Psychophysical bases of perceived exertion. Medicine And Science In Sports And Exercise, 14(5), 377-381

Carrasco, L., Sañudo, B., de Hoyo, M., Pradas, F., \& Da Silva, M. E. (2011). Effectiveness of low-frequency vibration recovery method on blood lactate removal, muscle contractile properties and on time to exhaustion during cycling at $\mathrm{VO} 2$ max power output. European Journal of Applied Physiology, 111(9), 2271-2279. https://doi.org/ 10.1007/s00421-011-1848-9

Cheng, C. F., Hsu, W. C., Lee, C. L., \& Chung, P. K. (2010). Effects of the different frequencies of whole-body vibration during the recovery phase after exhaustive exercise. The Journal of Sports Medicine and Physical Fitness, 50(4), 407-415

Cochrane, D J. (2011). Vibration exercise: the potential benefits. International Journal Of Sports Medicine, 32(2), 75-99. https:// doi.org/10.1055/s-0030-1268010

Cochrane, D. J. (2012). Is vibration exercise a useful addition to a weight management program? Scandinavian Journal of Medicine \& Science in Sports, 22(6), 705-713. https://doi.org/10.1111/j.16000838.2011.01411.x

Cochrane, Darryl J, \& Hawke, E. J. (2007). Effects of acute upper-body vibration on strength and power variables in climbers. Journal of Strength And Conditioning Research, 21(2), 527-531

Cohen, J. (1992). A power primer. Psychological Bulletin, 112(1), 155159. https://doi.org/10.1037/0033-2909.112.1.155

Coza, A., Nigg, B. M., \& Dunn, J. F. (2011). Effects of vibrations on gastrocnemius medialis tissue oxygenation. Medicine and Science in Sports and Exercise, 43(3), 509-515. https://doi.org/10.1249/ MSS.0b013e3181f2589f

Cristi-Montero, C., Rodriguez-Rodriguez, F., Mendoza-Muñoz, J., BarontiCorrea, F., Leiva-Olivares, S., Rojas-Hube, M., \& Bresciani, G. (2015). Blood lactate removal after a rowing all-out test depends on the active protocol proposed. Science \& Sports, 30(5), 283-289. https:/ /doi.org/10.1016/j.scispo.2014.12.003

Dupont, G., Moalla, W., Guinhouya, C., Ahmaidi, S., \& Berthoin, S. (2004). Passive versus Active Recovery during High-Intensity Intermittent Exercises: Medicine \& Science in Sports \& Exercise, 36(2), 302-308. https://doi.org/10.1249/ 01.MSS.0000113477.11431.59

Edge, J., Mündel, T., Weir, K., \& Cochrane, D. J. (2009). The effects of acute whole body vibration as a recovery modality following highintensity interval training in well-trained, middle-aged runners. European Journal of Applied Physiology, 105(3), 421-428. https:/ /doi.org/10.1007/s00421-008-0919-z

Faude, O., Kindermann, W., \& Meyer, T. (2009). Lactate Threshold Concepts. Sports Medicine, 39(6), 469-490. https://doi.org/10.2165/ 00007256-200939060-00003

Figueroa, A., Gil, R., Wong, A., Hooshmand, S., Park, S. Y., Vicil, F., \& Sanchez-Gonzalez, M. A. (2012). Whole-body vibration training reduces arterial stiffness, blood pressure and sympathovagal balance in young overweight/obese women. Hypertension Research, 35(6), 667-672. https://doi.org/10.1038/hr.2012.15

Forsyth, J. J., \& Farrally, M. R. (2000). A comparison of lactate concentration in plasma collected from the toe, ear, and fingertip after a simulated rowing exercise. British Journal of Sports Medicine, 34(1), 35-38. https://doi.org/10.1136/bjsm.34.1.35

Green, J. G., \& Stannard, S. R. (2010). Active Recovery Strategies and Handgrip Performance in Trained Vs. Untrained Climbers. The 
Journal of Strength \& Conditioning Research, 24(2), 494. https:// doi.org/10.1519/JSC.0b013e3181c06af3

Hall, M. M., Rajasekaran, S., Thomsen, T. W., \& Peterson, A. R. (2016). Lactate: Friend or Foe. PM\&R, 8(3, Supplement), S8-S15. https:// doi.org/10.1016/j.pmrj.2015.10.018

Hawkey, A. (2012). Whole body vibration training improves muscular power in a recreationally active population. Sportlogia, 8(2), 116122. https://doi.org/10.5550/sgia.120802.en.116H

Imai, K., Sato, H., Hori, M., Kusuoka, H., Ozaki, H., Yokoyama, H., Takeda, H., Inoue, M., \& Kamada, T. (1994). Vagally mediated heart rate recovery after exercise is accelerated in athletes but blunted in patients with chronic heart failure. Journal of the American College of Cardiology, 24(6), 1529-1535. https://doi.org/10.1016/07351097(94)90150-3

Javorka, M., Zila, I., Balhárek, T., \& Javorka, K. (2002). Heart rate recovery after exercise: relations to heart rate variability and complexity. Brazilian Journal of Medical and Biological Research, 35(8), 991-1000. https://doi.org/10.1590/S0100879X2002000800018

Jimenez, A., Gonzalez-Gallego, J., de Paz, J. A., Garatachea Vallejo, N., Bresciani, G., \& Gonzalez-Gallego, J. (2007). The effects of movement velocity during squatting on energy expenditure and substrate utilization in whole-body vibration. JOURNAL OF STRENGTH AND CONDITIONING RESEARCH, 21(2), 594-598

Kang, S. R., Min, J.-Y., Yu, C., \& Kwon, T.-K. (2017). Effect of whole body vibration on lactate level recovery and heart rate recovery in rest after intense exercise. Technology and Health Care, 25(S1), 115-123. https://doi.org/10.3233/THC-171313

Karvonen, M. J., Kentala, E., \& Mustala, O. (1957). The effects of training on heart rate; a longitudinal study. Annales Medicinae Experimentalis Et Biologiae Fenniae, 35(3), 307-315.

Kass, L., \& Carpenter, R. (2009). The Effect of Sampling Time on Blood Lactate Concentration ([Bla]) in Trained Rowers. International Journal of Sports Physiology and Performance, 4(2), 218-228. https://doi.org/10.1123/ijspp.4.2.218

Kellmann, M., Bertollo, M., Bosquet, L., Brink, M., Coutts, A. J., Duffield, R., Erlacher, D., Halson, S., Hecksteden, A., Heidari, J., Kallus, K., Meeusen, R., Mujika, I., Robazza, C., Skorski, S., Venter, R., \& Beckmann, J. (2018). Recovery and Performance in Sport: Consensus Statement. International Journal of Sports Physiology and Performance, 13(2), 240-245. https://doi.org/10.1123/ijspp.2017-0759

Lohman, E. B., 3rd, Petrofsky, J. S., Maloney-Hinds, C., Betts-Schwab, H., \& Thorpe, D. (2007). The effect of whole body vibration on lower extremity skin blood flow in normal subjects. Medical Science Monitor: International Medical Journal Of Experimental And Clinical Research, 13(2), CR71-CR76

Marin, P. J., Zarzuela, R., Zarzosa, F., Herrero, A. J., Garatachea, N., Rhea, M. R., \& García-López, D. (2012). Whole-body vibration as a method of recovery for soccer players. European Journal of Sport Science, 12(1), 2-8. https://doi.org/10.1080/17461391.2010.536579

McAinch, A. J., Febbraio, M. A., Parkin, J. M., Zhao, S., Tangalakis, K., Stojanovska, L., \& Carey, M. F. (2004). Effect of Active versus Passive Recovery on Metabolism and Performance during Subsequent Exercise. International Journal of Sport Nutrition and Exercise Metabolism, 14(2), 185-196. https://doi.org/10.1123/ijsnem.14.2.185

Menzies, P., Menzies, C., McIntyre, L., Paterson, P., Wilson, J., \& Kemi, O. J. (2010). Blood lactate clearance during active recovery after an intense running bout depends on the intensity of the active recovery. Journal of Sports Sciences, 28(9), 975-982. https://doi.org/10.1080/ 02640414.2010 .481721

Messonnier, L. A., Emhoff, C.-A. W., Fattor, J. A., Horning, M. A., Carlson, T. J., \& Brooks, G. A. (2013). Lactate kinetics at the lactate threshold in trained and untrained men. Journal of Applied Physiology, 114(11), 1593-1602. https://doi.org/10.1152/ japplphysiol.00043.2013

Mester, J., Kleinöder, H., \& Yue, Z. (2006). Vibration training: benefits and risks. Journal of Biomechanics, 39(6), 1056-1065. https://doi.org/ 10.1016/j.jbiomech.2005.02.015

Mika, A., Oleksy, £., Kielnar, R., Wodka-Natkaniec, E., Twardowska, M., Kamiñski, K., \& Ma3ek, Z. (2016). Comparison of Two Different Modes of Active Recovery on Muscles Performance after Fatiguing
Exercise in Mountain Canoeist and Football Players. PLOS ONE, 11(10), e0164216. https://doi.org/10.1371/journal.pone.0164216

Milanese, C., Cavedon, V., Sandri, M., Tam, E., Piscitelli, F., Boschi, F., \& Zancanaro, C. (2018). Metabolic effect of bodyweight whole-body vibration in a 20-min exercise session: A crossover study using verified vibration stimulus. PLOS ONE, 13(1), e0192046. https://doi.org/ 10.1371/journal.pone.0192046

Monedero, J., \& Donne. (2000). Effect of Recovery Interventions on Lactate Removal and Subsequent Performance. International Journal of Sports Medicine, 21(8), 593-597. https://doi.org/10.1055/s-20008488

Mota, M. R., Dantas, R. A. E., Oliveira-Silva, I., Sales, M. M., Sotero, R. da C., Venâncio, P. E. M., Junior, J. T., Chaves, S. N., \& de Lima, F. D. (2017). Effect of self-paced active recovery and passive recovery on blood lactate removal following a $200 \mathrm{~m}$ freestyle swimming trial. Open Access Journal of Sports Medicine, 8, 155-160. https://doi.org/ 10.2147/OAJSM.S127948

O’Leary, D. S. (1993). Autonomic mechanisms of muscle metaboreflex control of heart rate. Journal of Applied Physiology, 74(4), 17481754. https://doi.org/10.1152/jappl.1993.74.4.1748

Olivares-Arancibia, J., Solis-Urra, P., Rodriguez-Rodriguez, F., SantosLozano, A., Sanchez-Martinez, J., Martín-Hernández, J., ZuritaCovalán, N., Sadarangani, K., Cristi-Montero, C. (2018). A single bout of whole-body vibration improves hamstring flexibility in university athletes: A randomized controlled trial. https://doi.org/ 10.14198/jhse.2018.134.06

Pyne, D. B., Boston, T., Martin, D. T., \& Logan, A. (2000). Evaluation of the Lactate Pro blood lactate analyser. European Journal of Applied Physiology, 82(1), 112-116. https://doi.org/10.1007/ s004210050659

Rauch, F., Sievanen, H., Boonen, S., Cardinale, M., Degens, H., Felsenberg, D., Roth, J., Schoenau, E., Verschueren, S., \& Rittweger, J. (2010). Reporting whole-body vibration intervention studies: Recommendations of the International Society of Musculoskeletal and Neuronal Interactions. JOURNAL OF MUSCULOSKELETAL \& NEURONAL INTERACTIONS, 10. Recuperado de https://espace.mmu.ac.uk/595958/

Robergs, R. A., Ghiasvand, F., \& Parker, D. (2004). Biochemistry of exercise-induced metabolic acidosis. American Journal of PhysiologyRegulatory, Integrative and Comparative Physiology, 287(3), R502R516. https://doi.org/10.1152/ajpregu.00114.2004

Ross, A., \& Leveritt, M. (2001). Long-Term Metabolic and Skeletal MuscleAdaptations to Short-Sprint Training. Sports Medicine, 31(15), 1063-1082. https://doi.org/10.2165/00007256-200131150-00003

Sañudo, B., César-Castillo, M., Tejero, S., Nunes, N., de Hoyo, M., \& Figueroa, A. (2013). Cardiac autonomic response during recovery from a maximal exercise using whole body vibration. Complementary Therapies in Medicine, 21(4), 294-299. https://doi.org/10.1016/ j.ctim.2013.05.004

Sañudo, B., César-Castillo, M., Tejero, S., Cordero-Arriaza, F. J., OlivaPascual-Vaca, Á., \& Figueroa, A. (2016). Effects of Vibration on Leg Blood Flow After Intense Exercise and Its Influence on Subsequent Exercise Performance. The Journal of Strength \& Conditioning Research, 30(4), 1111. https://doi.org/10.1519/ JSC.0b013e3182a20f2c

Savin, W. M., Davidson, D. M., \& Haskell, W. L. (1982). Autonomic contribution to heart rate recovery from exercise in humans. Journal of Applied Physiology, 53(6), 1572-1575. https://doi.org/10.1152/ jappl.1982.53.6.1572

Schulz, K. F., Altman, D. G., \& Moher, D. (2011). CONSORT 2010 statement: Updated guidelines for reporting parallel group randomised trials. International Journal of Surgery, 9(8), 672-677. https://doi.org/ 10.1016/j.ijsu.2011.09.004

Spencer, M., Dawson, B., Goodman, C., Dascombe, B., \& Bishop, D. (2008). Performance and metabolism in repeated sprint exercise: effect of recovery intensity. European Journal of Applied Physiology, 103(5), 545-552. https://doi.org/10.1007/s00421-008-0749-z

World MedicalAssociation. (2013). World Medical Association Declaration of Helsinki: ethical principles for medical research involving human subjects. JAMA, 310(20), 2191-2194. https://doi.org/10.1001/ jama.2013.281053 